\title{
LATE COMPLICATIONS OF PROLONGED TRACHEAL INTUBATION
}

\author{
G.R. Sellery, A. Worth, and R.E. Greenway
}

OVER THE LAST SIX YEARS the accepted time limit for tracheal intubation of critically ill patients in our hospital has increased from 48 hours 10 periods of seven to ten days. The problem associated with prolonged tracheal intubation as compared to tracheostomy was felt to be laryngeal damage caused by pressure of the tracheal tube on the posterior aspects of the cords and the arytenoid cartilages.' Many previous studies have compared the complications of prolonged tracheal intubation with the complications of tracheostomy. ${ }^{2.3}$ Most studies, however, have considered the respiratory status and other problems such as laryngeal competence and talking while the patient was still in the hospital. ${ }^{4}$ This study was designed to assess patients' problems over a much longer period of time. ${ }^{5}$ In our study of these problems we posed a number of questions. Did the prolonged tracheal intubation result in acute damage to the larynx? Did the prolonged intubation result in any late complications after the patient had been discharged from hospital? Was there any relationship between the acute lesions seen in the laryn $x$ and late complications? Did tracheostomy after seven to ten days of tracheal intubation increase the late complications?

\section{Criteria for Study}

The patients selected for study were in the Intensive Care Unit during the years 1973 to 1976 inclusive. All patients were over the age of 15 years and had no pre-existing airway disease. All patients studied had tracheal tubes in place for at least three days. Patients who subsequently required tracheostomy were included, whereas those who died during their stay in the Intensive Care Unit, the hospital ward or before receiving a questionnaire after discharge from hospital, were excluded from the study.

G.R. Sellery. M.D., F.R.C.P.(C) and A. Worth, B.Sc., Department of Anaesthesia, and R.E. Greenway, M.D., F.R.C.S.(C), Department of Otolaryngology, Victoria Hospital, London, Ontario.

Reprint requests should be addressed to Dr. G.R. Sellery, Department of A naesthesia, Victoria Hospital, London, Ontario, N6A 4G5.

Canad. Anaesth. Soc. J., vol. 25, no. 2, March 1978

\section{METHODS}

The patients were managed in a large multidisciplinary Intensive Care Unit where artificial airway care was standardized as much as possible with regard to suctioning, humidification and cuff deflation. Tracheal tubes were standard polyvinylchloride tubes which conformed relatively easily to the anatomy of the airway at body temperature. Every effort was made by sedation and occasionally by muscle paralysis to reduce the movement of the tube within the patient's larynx.

After approximately one week of intubation, most of the patients were seen by the otolaryngology service and the larynx was assessed by direct laryngoscopy. The tracheal tube was changed. Only patients who had been intubated for longer than three days were considered in this study and some patients, who were not intubated for the full seven days, were not examined by the otolaryngologist.

The hospital records of discharged patients were reviewed to assess airway complications in hospital. Problems such as stridor, hoarseness, difficulty in swallowing and laryngeal competence were noted.

A questionnaire was sent to each of these patients so that they could report complaints referable to breathing, talking, swallowing, coughing and other problems. The patient was asked to note whether these complaints were worse following discharge than they were on admission. Information was solicited regarding the increase in severity and the duration of the complaints (Table I). The patients were then asked to have a further indirect laryngoscopy by the otolaryngology service to assess the degree of abnormality, if any.

\section{REsults}

The results are summarized in Table II which shows the number of patients studied and the disposition of the questionnaires.

The number and type of complaints by patients who had been intubated are noted in Table III. 
TABLE I

Abbreviated Questionnaire

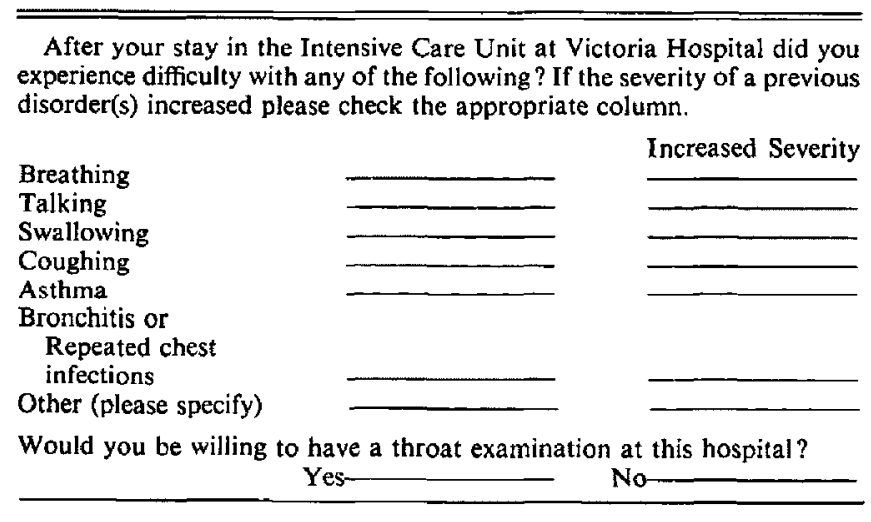

These are complaints of increased severity or are new, relative to the patient's condition prior to intubation. They are divided into those intubated for seven or more days and those intubated for a shorter time. The incidence of pathology of the larynx at the follow-up visit of 21 of these patients is shown in Table IV. The follow-up visits occurred in 1976, so that some patients may have been discharged up to three years previously.

The number and type of complaints of patients who had tracheostomies following intubation are shown in Table V. The results from the review of hospital records were inconclusive since many of the laryngoscopies after one week of intubation were not recorded in the early years. However, it can be assumed that the patients requiring tracheostomy after seven days of intubation had significant pathology to justify the surgery.

Table VI shows the small number of patients found from the hospital records to have significant pathology who did not have a tracheostomy.

\section{Discussion}

Over the years studied it has been the practice in our institution to manage patients requiring

\section{TABLE II}

Results

\begin{tabular}{lr}
\hline $\begin{array}{l}\text { No. of patients studied } \\
\quad \text { (questionnaires sent) }\end{array}$ & 237 \\
No. of questionnaires returned & 120 \\
No. of deaths since discharge & \\
$\quad$ (noted from questionnaire) & 24 \\
No. of patients responding & 96 \\
No. of patients seen at follow-up & 21 \\
\hline
\end{tabular}

artificial ventilation with a polyvinylchloride tracheal tube with a high compliance cuff (Portex or American Hospital). Patients were left intubated for seven days, at which time the larynx was examined. At that time the decision was made as to whether a tracheostomy should be done. If the patient showed significant pathology such as ulceration of the cords or arylenoids, a tracheostomy was advised. If there were no significant changes and if the patient was involved in the weaning process the airway was maintained with a tracheal tube.

With this practice the number of tracheostomies done was significantly reduced. We thus avoided the well-known complications of tracheostomy in these patients. There was some concern, however, that those patients who showed significant changes in the larynx before tracheostomy might develop later complications such as granuloma or laryngeal stenosis. This was not the case, as noted from the questionnaires sent out to the patients. There were no cases of laryngeal stenosis and only one case where a granuloma required surgical treatment. Minor complaints such as mild hoarseness did occur for varying lengths of time.

The chart review was inconclusive as many of the records of patients assessed by laryngoscopy at one week did not have a written record of this. A large number of those assessed who required intubation for seven days or more either died or did not respond to the questionnaire. Therefore the number of patients who were assessed at one week by laryngoscopy and subsequently responded to the questionnaire was small. However, five of those patients examined at one week who had significant pathological changes in the 
TABLE III

Patients' Complatnts Noted on Questionnatre (INCREASED SEVERITY OR NEW)

\begin{tabular}{lcc}
\hline \hline \multicolumn{1}{c}{ INTURATION ALONE } & $\begin{array}{c}\text { Less than } 7 \text { days } \\
\text { (52 patients) }\end{array}$ & $\begin{array}{c}7 \text { days or greater } \\
\text { (17 patients) }\end{array}$ \\
Talking & 6 & 9 \\
Breathing & 5 & 3 \\
Coughing & 7 & 3 \\
Swallowing & 9 & 2 \\
Chest Infection & 3 & 1 \\
Nil & 33 & 8 \\
And without complication & $63 \%$ & $48 \%$ \\
\hline
\end{tabular}

TABLE IV

FOLLOW-UP LARYNGOSCOPY - PATHOLOGY

\begin{tabular}{lcc}
\hline \multicolumn{1}{c}{ INTubation aLoNe } & Less than 7 days & 7 days or greater \\
No. of patients & 16 & 5 \\
Nil & 12 & 4 \\
Minor & 3 & 1 \\
Major & 1 & 0 \\
Nil & $75 \%$ & $80 \%$ \\
\hline
\end{tabular}

TABLE $V$

Patient Complaints Noted on Questionnaire (INCREASED SEVERITY OR NEW)

\begin{tabular}{lcc}
\hline $\begin{array}{l}\text { TRACHEOSTOMY } \\
\text { FOLLOWING INTUBATION }\end{array}$ & $\begin{array}{c}\text { Less than 7 days } \\
\text { (6 patients) }\end{array}$ & $\begin{array}{c}7 \text { days or greater } \\
\text { (17 patients) }\end{array}$ \\
\hline Talking & 2 & 8 \\
Breathing & 3 & 2 \\
Coughing & 1 & 5 \\
Swallowing & - & 4 \\
Chest Infections & - & 1 \\
Nil & 1 & 4 \\
\% Without complication & $17 \%$ & $23 \%$ \\
\hline
\end{tabular}

TABLE VI

Chart Review - Patients With Laryngeal Pathology (At One Week) No Tracheostomy

\begin{tabular}{lll}
\hline & \multicolumn{1}{c}{ Pathology } & \multicolumn{1}{c}{ Complaint } \\
\hline L.D. & Oedema of cords & Nil \\
L.J.S. & Ulceration of cords & Slight hoarseness \\
G.S. & Oedema of cords & Nil \\
D.K. & Ulceration (L) vocal cord & Nil \\
V.A.W. & Oedema of cords & Nil \\
W.L. & Ulceration (R) vocal cord & Slight hoarseness \\
R.V.H. & Small granuloma & Hoarseness \\
T.B. & Ulceration of cords & Hoarseness \\
E.D. & Oedema of cords & Hoarseness \\
B.K. & Ulceration of cords & Nil \\
N.R. & Ulceration of cords & Hoarseness \\
\hline
\end{tabular}


larynx had no complaints. Patients who were not assessed at one week therefore provided most of the respondents for questionnaires and also cooperated by returning for indirect laryngoscopy.

One concern that became apparent was noted in patients who had been intubated for seven days or more and who then required a tracheostomy. These patients had significant laryngeal pathology, so that tracheostomy was advised. After tracheostomy, the larynx was left "unused" with respect to gas flow and more significant degrees of hoarseness were noted. However, even in this situation, no serious stenosis occurred. It was apparent, however, that the number of patients studied was small due to the high mortality in this group.

\section{Conclusion}

It is apparent that granuloma and laryngeal stenosis are uncommon as late complications of prolonged tracheal intubation. Patients with tracheal tubes in place for seven days should have a direct laryngoscopy and the tube should be changed. Pathological changes seen on this examination do not indicate that late complications involving the larynx will ensue. A firm opinion on whether a tracheostomy should be done when significant pathological changes are seen after seven days must await the accumulation of more cases. It appears that when no significant laryngeal pathology is seen at the examination on the seventh day, tracheal intubation can be continued until a second examination is carried out in about five days.

\section{SUMMARY}

Questionnaires were sent to patients who had tracheal intubation for periods longer than three days in a large multidisciplinary Intensive Care Unit. The information sought was of complaints related to talking, breathing, coughing, swallowing and chest infection. Of patients who had been intubated for seven days or less, 63 per cent of the 52 patients responding had no complications while only one of the remainder had a major complication requiring surgical removal of a granuloma. Forty-eight per cent of patients intubated for more than seven days had no complaints and the rest of the patients had minor complaints which did not persist. Most complained of hoarseness. Of patients who had a tracheostomy following prolonged intubation, only 23 per cent were free of complications. From this it is concluded that tracheal tubes can be left in place for seven days and at this time direct laryngoscopy should be done. If no significant laryngeal pathology is seen at this examination, tracheal intubation may be continued.

\section{RÉSUMÉ}

Nous avons fait parvenir un questionnaire aux malades ayant été intubés plus de trois jours, avec ou sans trachéostomie subséquente, au cours de leur séjour dans une unité de soins intensifs multidisciplinaire. Les questions cherchaient à mettre en évidence les complications liées à l'intubation prolongée ou à la trachéostomie, à savoir des problèmes de phonation, de respiration, de toux, de déglutition ou d'infection.

Chez les malades intubés moins de sept jours, 63 pour cent de ceux qui ont répondu au questionnaire (52 malades) n'ont rapporté aucune complication; une seule complication majeure, soit un granulome ayant nécessité une excision chirurgicale, a été retenue chez les malades de ce groupe qui ont rapporté des complications.

Chez les malades intubés plus de sept jours, 48 pour cent disaient $n^{\dagger}$ avoir présenté aucune complication, alors que les autres n'avaient que des problèmes mineurs à rapporter (le plus souvent une raucité de la voix). Seulement 23 pour cent des malades ayant subi une trachéostomie à la suite d'une intubation prolongée n'avaient pas de complications à rapporter.

Nous concluons que les tubes endotrachéaux peuvent être laissés en position durant sept jours. Après ce temps, l'on devrait procéder à une laryngoscopie sous vision directe. Si cet examen ne met pas en évidence de pathologie laryngée significative, l'intubation trachéale peut être continuée.

\section{REFERENCES}

1. Lindholm, C.E. Prolonged endotracheal intubation. Acta Anaesthesiol. Scand. Supp. 32: 25 (1969).

2. Harrison, G.A. \& Tonkin, J.P. Prolonged (therapeutic) endotracheal intubation. Br. J. Anaes. 40:24I (1968).

3. Glas, W.W., King, O.J. Jr., \& LuI, A. Complicalions of tracheostomy. Arch. Surg. 85: 56 (1962),

4. El-Nagger, M. Sadagopan, S., Levine, H., KANTOR, H., \& Collins, V.J. Factors influencing choice between tracheostomy and prolonged translaryngeal intubation in acute respiratory failure: a prospective study. Anes. \& Analg. 55: 195 (1976).

5. Sellery, G.R. \& Baker. B.L. Endotracheal intubation for 31 days in a tetanus patient. Canad. Anaes. Soc. J. 18: 683 (1971). 